\title{
Efficiency of a mechanical device in controlling tracheal cuff pressure in intubated critically ill patients: a randomized controlled study
}

Saad Nseir ${ }^{1,2^{*}}$, Andrey Rodriguez ${ }^{1}$, Paula Saludes ${ }^{1}$, Julien De Jonckheere ${ }^{3}$, Jordi Valles ${ }^{1}$, Antonio Artigas ${ }^{1}$ and Ignacio Martin-Loeches ${ }^{4}$

\section{Abstract}

Background: Cuff pressure $\left(P_{\text {cuff }}\right)$ control is mandatory to avoid leakage of oral secretions passing the tracheal tube and tracheal ischemia. The aim of the present trial was to determine the efficacy of a mechanical device (PressureEasy ${ }^{\oplus}$ ) in the continuous control of $P_{\text {cuff }}$ in patients intubated with polyvinyl chloride (PVC)-cuffed tracheal tubes, compared with routine care using a manometer.

Methods: This is a prospective, randomized, controlled, cross-over study. All patients requiring intubation with a predicted duration of mechanical ventilation $\geq 48 \mathrm{~h}$ were eligible. Eighteen patients randomly received continuous control of $P_{\text {cuff }}$ with PressureEasy ${ }^{\circledR}$ device for $24 \mathrm{~h}$, followed by discontinuous control (every $4 \mathrm{~h}$ ) with a manual manometer for $24 \mathrm{~h}$, or vice versa. $P_{\text {cuff }}$ and airway pressure were continuously recorded. $P_{\text {cuff }}$ target was $25 \mathrm{cmH}_{2} \mathrm{O}$ during the two periods.

Results: The percentage of time spent with $P_{\text {cuff }} 20-30 \mathrm{cmH}_{2} \mathrm{O}$ (median (IQR) $34 \%$ (17-57) versus $50 \%$ (35-64), $p=0.184)$ and the percentage of time spent with $P_{\text {cuff }}<20 \mathrm{cmH}_{2} \mathrm{O}(23 \%(5-63)$ versus $43 \%(16-60)$, $p=0.5)$ were similar during continuous control of $P_{\text {cuff }}$ and routine care, respectively. However, the percentage of time spent with $P_{\text {cuff }}>30 \mathrm{cmH}_{2} \mathrm{O}$ was significantly higher during continuous control compared with routine care of tracheal cuff (26\% (14-39) versus $7 \%(1-18), p=0.002)$. No significant difference was found in $P_{\text {cuff }}(25$ (18-28) versus 21 $(18-26), p=0.17)$, mean airway pressure $(14(10-17)$ versus $14(11-16), p=0.679)$, or coefficient of variation of $P_{\text {cuff }}$ (19\% (11-26) versus $20 \%(11-25), p=0.679)$ during continuous control compared with routine care of tracheal cuff, respectively.

Conclusions: PressureEasy ${ }^{\otimes}$ did not demonstrate a better control of $P_{\text {cuff }}$ between 20 and $30 \mathrm{cmH}_{2} \mathrm{O}$, compared with routine care using a manometer. Moreover, the device use resulted in significantly higher time spent with overinflation of tracheal cuff, which might increase the risk for tracheal ischemic lesions.

Trial registration: Clinicaltrial.gov: NCT02109003

Keywords: Cuff pressure; Control; Tracheal ischemia; Microaspiration; Mechanical ventilation

\footnotetext{
* Correspondence: s-nseir@chru-lille.fr

${ }^{1}$ Critical Care Center, Hospital de Sabadell, Universidad Autonoma de

Barcelona, CIBER enfermedades respiratorias, Corporació Sanitaria Parc Tauli,

Parc Tauli 1, 08208 Sabadell, Spain

${ }^{2}$ Critical Care Center, R. Salengro Hospital, CHRU de Lille, rue E. Laine, 59037

Lille Cedex, France

Full list of author information is available at the end of the article
} 


\section{Background}

Intubation is an invasive procedure that is still performed in a large proportion of critically ill patients [1]. Some long-term intubation-related complications are caused by inappropriate cuff pressure $\left(P_{\text {cuff }}\right)$, and include microaspiration, and tracheal ischemic lesions $[2,3]$. Microaspiration of contaminated oropharyngeal secretions is the main route of entry for bacteria into the lower respiratory tract $[4,5]$. Colonization of the lower respiratory tract could progress into ventilatorassociated pneumonia (VAP) when local or general defense mechanisms are altered in intubated critically ill patients [6]. VAP is the most frequent infection acquired in the ICU and is associated with high morbidity and mortality, especially in patients with comorbidities [7]. Tracheal ischemic injury is also associated with high morbidity, especially when routine care for tracheal cuff is not adequately provided [8-11].

Based on international recommendations, $P_{\text {cuff }}$ should be kept between 20 and $30 \mathrm{cmH}_{2} \mathrm{O}$ using a manometer [12, 13]. However, several recent studies suggested that a noncontinuous control of $P_{\text {cuff }}$ using a manometer is not effective in intubated critically ill patients [14]. Further, previous studies did not identify modifiable risk factors for overinflation or underinflation of tracheal cuff [15-18].

Recently, several devices allowing continuous control of $P_{\text {cuff }}$ were evaluated [19-22]. These devices are classified into pneumatic (i.e., does not require power supply, but a single-use 200-ml cylindrical cuff) and electronic devices (requiring power supply). Two prospective randomized controlled animal and human studies first validated the use of a pneumatic device $[19,20]$. A noncommercially available device has also been validated and proved to be efficient in continuously controlling

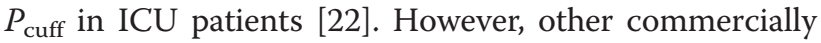
available automated devices were only validated in in vitro studies $[23,24]$. Recent data suggest that these devices interfere with the self-sealing characteristics of high-volume low-pressure (HVLP) tracheal cuffs [23]. Further, these electronic devices have been shown to be less efficient than the pneumatic device in continuous control of $P_{\text {cuff }}$, because of rapid correction of overinflation episodes [21].

A new mechanical device with an improved design aiming at continuously controlling $P_{\text {cuff }}$ has been commercialized (PressureEasy ${ }^{\circ}$, Smiths medical). The advantages of using such device are its small size and lower cost compared with other devices. However, to our knowledge, no study has evaluated the efficiency of this device in controlling $P_{\text {cuff. }}$ Therefore, we conducted this prospective randomized cross-over study to determine the efficiency of this device in continuously controlling $P_{\text {cuff. }}$ Our hypothesis was that this mechanical device would allow significant reduction of time spent with underinflation or overinflation of $P_{\text {cuff, }}$ compared with routine care, using a manual manometer.

\section{Methods}

\section{Ethical aspects}

This prospective randomized controlled study was performed in a 16-bed ICU of the teaching hospital of Sabadell (Spain), from April 2014 to July 2014. The institutional review board of the Parc Tauli University Hospital approved the study. Written consent was obtained from the patients or from their next of kin (ClinicalTrials.gov identifier: NCT02109003 http:// clinicaltrials.gov/show/NCT02109003).

\section{Inclusion and exclusion criteria}

All patients older than 18 years who were intubated with a predicted duration of mechanical ventilation $\geq 48 \mathrm{~h}$ were eligible for the study. Patients were excluded if they (1) were admitted to the ICU with a previous tracheostomy, (2) were enrolled in another study that might influence this study results, or (3) were intubated and mechanically ventilated $>48 \mathrm{~h}$ at the time of randomization.

\section{Randomization}

Patients were randomly assigned to receive continuous control of $P_{\text {cuff }}$ with the mechanical device (PressureEasy ${ }^{\circ}$ ) (Fig. 1) for $24 \mathrm{~h}$, followed by discontinuous control (every $4 \mathrm{~h}$ ) with a manual manometer (Hi-Lo Hand Pressure Gauge, Covidien, TM, Malinckrodt TM) for $24 \mathrm{~h}$; or discontinuous control of $P_{\text {cuff }}$ followed by continuous control of $P_{\text {cuff. The }}$ target of $P_{\text {cuff }}$ was 25 $\mathrm{cmH}_{2} \mathrm{O}$ during the two periods. Randomization was performed using a computer-generated random assignment list in balanced blocs of four. Treatment assignments were contained in sealed opaque envelopes sequentially numbered.

PressureEasy ${ }^{\circ}$ is a single-patient use device, designed to continuously monitor tracheal $P_{\text {cuff. Its indicator win- }}$ dow signals that $P_{\text {cuff }}$ is maintained between 20 and 30 $\mathrm{cmH}_{2} \mathrm{O}$. In addition, the airway pressure auto-feedback feature boosts $P_{\text {cuff }}$ to ensure proper sealing when high pressures are used during ventilation. A pressure feedback line is designed to eliminate cuff leaks at peak inspiratory pressure.

\section{Outcome measurement}

In order to determine the percentage of patients with underinflation and overinflation of tracheal cuff and the duration of these episodes, the $P_{\text {cuff }}$ and the airway pressure were continuously recorded at a digitizing frequency of $100 \mathrm{~Hz}$ for $48 \mathrm{~h}$ (Physiotrace; Estaris, Lille, France) [25], including $24 \mathrm{~h}$ of continuous control of 


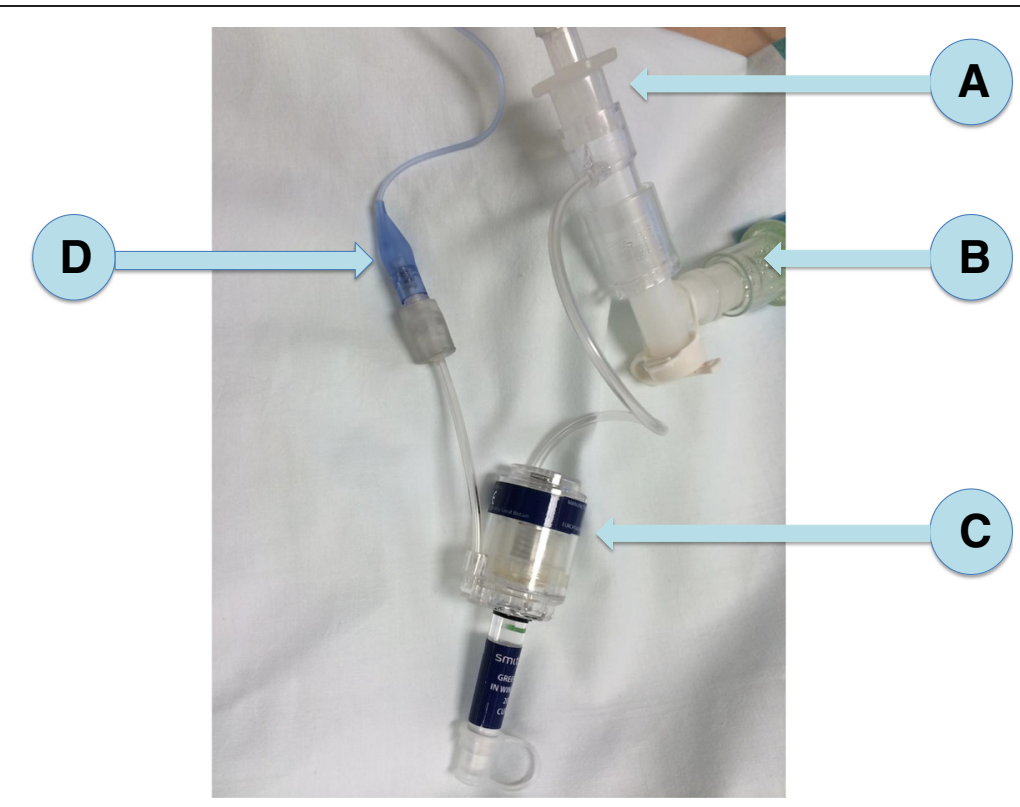

Fig. 1 The PressureEasy ${ }^{\oplus}$ device. a Tracheal tube, (b) ventilator circuit, (c) PressureEasy ${ }^{\oplus}$, and (d) external tracheal cuff

$P_{\text {cuff }}$ using the mechanical device and $24 \mathrm{~h}$ of manual control of $P_{\text {cuff }}$ using the manometer. The connection between the pressure transducer and the tracheal cuff was identical in the two study periods, with a three-way stopcock of which the third port was either connected to the mechanical device or closed and connected to the manometer every $4 \mathrm{~h}$ (Fig. 2). A second pressure transducer was connected to the heat and moisture exchanger, in order to record respiratory pressure. Pressure transducers were connected to a laptop, in order to continuously transfer pressure-time curves and mean values. Connections were checked every $4 \mathrm{~h}$. The engineer who analyzed the data (JDJ), using the same program, was blinded to the randomization order.

\section{Study population}

All the patients were intubated with a high-volume lowpressure PVC-cuffed tracheal tube with continuous subglottic secretion drainage (TaperGuard Evac, Covidien, Mallinckrodt) and were included within the first $48 \mathrm{~h}$ of intubation. Tracheal tube size was 8 and 7.5 in men and women, respectively. During the manometer period, nurses adjusted $P_{\text {cuff }}$ every $4 \mathrm{~h}$. Tracheal suctioning was performed six times a day or more frequently if clinically indicated.

\section{Other definitions}

Underinflation of tracheal cuff was defined as $P_{\text {cuff }}<20$ $\mathrm{cmH}_{2} \mathrm{O}$ for $>5$ min over the 24-h period of recording. Overinflation of tracheal cuff was defined as $P_{\text {cuff }}>30$ $\mathrm{cmH}_{2} \mathrm{O}$ for $>5$ min over the 24-h period of recording [14].
The primary objective was to determine the efficiency of the mechanical device in reducing the percentage of time spent with underinflation or overinflation of tracheal cuff, compared with routine care using a manometer. The secondary objective was to determine the efficiency of the mechanical device in reducing the percentage of patients with underinflation or overinflation of tracheal cuff, compared with routine care.

The coefficient of variation of $P_{\text {cuff }}$ was calculated as standard deviation/mean $P_{\text {cuff }} \times 100$.

\section{Statistical analyses}

\section{Sample size calculation}

Based on unpublished preliminary results, the mean percentage of time spent with underinflation or overinflation of tracheal cuff was $30 \%$ (SD $20 \%$ ) in patients intubated with a PVC-cuffed tracheal tube receiving routine care of $P_{\text {cuff }}$ using a manual manometer. The expected mean percentage of time with underinflation or overinflation of tracheal cuff using the mechanical device was $10 \%$ (expected difference of $20 \%$ ). Considering a power of $90 \%$ and an alpha risk of $5 \%$, the inclusion of 22 patients was required in a parallel-group design. However, when we took into account the cross-over design, the number of patients to include was 18 .

\section{Result analysis}

All analyses were performed in an intention-to-treat manner. Distribution of quantitative variables was tested using the Shapiro-Wilk test. Normally and nonnormally distributed variables were expressed as mean \pm SD and median (25th, 75th interquartile), respectively. The 




Fig. 2 Description of connections between pressure transducers, ventilator, and tracheal tube. a Tracheal tube, (b) connection between external cuff and the three-way stopcock, (c) ventilator, (d) three-way stopcock, (e) PressureEasy ${ }^{\circledast}$ device or manometer, (f) pressure transducers connected to the ventilator and to tracheal cuff, and (g) laptop

difference between the two groups was considered as significant if $p<0.05$. McNemar and Wilcoxon tests were used to compare qualitative and quantitative variables between the two 24-h periods, respectively.

We calculated the median (25th, 75th interquartile) value of mean airway pressure in all patients and considered patients with airway pressure $>75$ th interquartile as patients with high airway pressure. In order to determine the impact of high airway pressure on the efficiency of the mechanical device, we repeated all statistical analyses after exclusion of patients with high airway pressure.

\section{Results}

\section{Patient characteristics}

Eighteen patients were included in this study. Their mean age was $62 \pm 12$ years. At ICU admission, SAPS II and SOFA scores were $51 \pm 14$ and $7.7 \pm 3.1$, respectively. Duration of mechanical ventilation and ICU stay were $25 \pm 18$ days and $33 \pm 21$ days, respectively. No significant difference was found between the two study periods regarding the percentage of patients receiving sedation or neuromuscular-blocking agents. Glasgow Coma score, SOFA score, and PEEP were also similar during the two periods (Table 1). All patients received assist-control ventilation during the recording period. No significant difference was found in mean airway pressure between the two study periods (Table 2.)

\section{Impact of the mechanical device on $P_{\text {cuff }}$}

No significant difference was found in mean $P_{\text {cuff, }}$ percentage of time spent with $P_{\text {cuff }}$ between 20 and 30 $\mathrm{cmH}_{2} \mathrm{O}$, percentage of time spent with $P_{\text {cuff }}<20 \mathrm{cmH}_{2} \mathrm{O}$, or coefficient of variation of $P_{\text {cuff. }}$ The percentage of time spent with $P_{\text {cuff }}>30 \quad \mathrm{cmH}_{2} \mathrm{O}$ was significantly higher during continuous control compared with routine care of tracheal cuff (Table 2). No significant difference was found in the percentage of patients with $P_{\text {cuff }} 20-30$ $\mathrm{cmH}_{2} \mathrm{O}, P_{\text {cuff }}<20 \mathrm{cmH}_{2} \mathrm{O}$, or $P_{\text {cuff }}>30 \mathrm{cmH}_{2} \mathrm{O}$ during continuous control of $P_{\text {cuff }}$ and routine care (Table 2). No significant difference was found in the number of 
Table 1 Patient characteristics during the $48 \mathrm{~h}$ following randomization

\begin{tabular}{|c|c|c|c|}
\hline \multirow[t]{2}{*}{ Variables } & $\begin{array}{l}\text { Continuous } \\
\text { control of } P_{\text {cuff }}\end{array}$ & Routine care & \multirow[t]{2}{*}{$\begin{array}{l}p \\
\text { values }\end{array}$} \\
\hline & $n=18$ & $n=18$ & \\
\hline SOFA score & $8.8 \pm 3.4$ & $9 \pm 3.7$ & 0.458 \\
\hline Sedation & $14(77)$ & $14(77)$ & $>0.999$ \\
\hline $\begin{array}{l}\text { Neuromuscular-blocking } \\
\text { agent use }\end{array}$ & $1(5)$ & $0(0)$ & $>0.999$ \\
\hline Glasgow coma score ${ }^{a}$ & $7.5 \pm 3$ & $9 \pm 3.7$ & 0.137 \\
\hline PEEP & $6.7 \pm 1.9$ & $6.6 \pm 1.9$ & 0.157 \\
\hline
\end{tabular}

Data are frequencies (\%) or mean \pm SD

SOFA sequential organ failure assessment, PEEP positive

end-expiratory pressure

${ }^{\text {a }}$ The verbal response was evaluated as in intubated patients: 1 no answer,

2 seems able to give simple responses, and 5 seems able to speak

underinflation episodes between continuous control and routine care periods (median (IQR) $0(0,5)$ versus 2 $(0,7), p=0.733)$.

\section{Subgroup analysis}

After exclusion of the four patients with high mean airway pressure $\left(>17 \mathrm{cmH}_{2} \mathrm{O}\right)$, no significant difference was found in mean $P_{\text {cuff }}(26(18,28)$ versus $22(19,27)$ $\left.\mathrm{cmH}_{2} \mathrm{O}, p=0.177\right)$, percentage of time spent with $P_{\text {cuff }}$ between 20 and $30 \mathrm{cmH}_{2} \mathrm{O}(50(24,58)$ versus 53 (24, $71), p=0.124)$, percentage of time spent with $P_{\text {cuff }}<20$ $\mathrm{cmH}_{2} \mathrm{O}(16(2,51)$ versus $35(9,51), p=0.3)$, or

Table 2 Impact of the mechanical device on tracheal cuff pressure

\begin{tabular}{|c|c|c|c|}
\hline \multirow[t]{2}{*}{ Variables } & \multirow{2}{*}{$\begin{array}{l}\text { Continuous } \\
\text { control of } P_{\text {cuff }} \\
n=18\end{array}$} & \multirow{2}{*}{$\begin{array}{l}\text { Routine care } \\
n=18\end{array}$} & \multirow[t]{2}{*}{$\begin{array}{l}P \\
\text { values }\end{array}$} \\
\hline & & & \\
\hline $\begin{array}{l}\text { Mean airway pressure, } \\
\mathrm{CmH}_{2} \mathrm{O}\end{array}$ & $14(10-17)$ & $14(11-16)$ & 0.679 \\
\hline Mean $P_{\text {cuff, }} \mathrm{CmH}_{2} \mathrm{O}$ & $25(18,28)$ & $21(18,26)$ & 0.17 \\
\hline $\begin{array}{l}\text { Coefficient of variation } \\
\text { of } P_{\text {cuff, }} \%\end{array}$ & $19(11,26)$ & $20(12,25)$ & 0.67 \\
\hline \multicolumn{4}{|l|}{$P_{\text {cuff }} 20-30 \mathrm{cmH}_{2} \mathrm{O}$} \\
\hline$Y_{e s}^{a}$ & $18(100)$ & $18(100)$ & NA \\
\hline$\%$ of time ${ }^{b}$ & $34(17,57)$ & $50(35,64)$ & 0.184 \\
\hline \multicolumn{4}{|l|}{$P_{\text {cuff }}<20, \mathrm{cmH}_{2} \mathrm{O}$} \\
\hline Yes $^{\mathrm{a}}$ & $17(94)$ & $18(100)$ & $>0.999$ \\
\hline$\%$ of time & $23(5,63)$ & $43(16,60)$ & 0.528 \\
\hline \multicolumn{4}{|l|}{$P_{\text {cuff }}>30, \mathrm{cmH}_{2} \mathrm{O}$} \\
\hline$Y_{e s}^{a}$ & $18(100)$ & $16(89)$ & 0.500 \\
\hline$\%$ of time $e^{b}$ & $26(14,40)$ & $7(1,18)$ & 0.002 \\
\hline
\end{tabular}

Data are frequencies (\%) or median (interquartile range)

$P_{\text {cuff }}$ cuff pressure, $N A$ not applicable

${ }^{a} Y e s$ indicates the number of patients with at least one $P_{\text {cuff }} 20-30,>20$, or $>30 \mathrm{cmH}_{2} \mathrm{O}$

$\mathrm{b}_{\%}$ of time indicates all the time spent with $P_{\text {cuff }} 20-30,>20$, or $>30 \mathrm{cmH}_{2} \mathrm{O}$ reported to the total recording time during each study period coefficient of variation of $P_{\text {cuff }}(15(10,22)$ versus $16(10$, 24), $p=0.363)$. The percentage of time spent with $P_{\text {cuff }}>30 \mathrm{cmH}_{2} \mathrm{O}$ was still significantly higher during continuous control compared with routine care of tracheal cuff $(31(18,42)$ versus $8(3,20), p=0.006)$.

\section{Discussion}

The results of our study suggest that PressureEasy ${ }^{\oplus}$ was not more efficient in maintaining $P_{\text {cuff }}$ within the recommended range $\left(20-30 \mathrm{cmH}_{2} \mathrm{O}\right)$ than routine care of tracheal cuff using a manometer every $4 \mathrm{~h}$. No significant difference was found between continuous control of $P_{\text {cuff }}$ using the mechanical device and routine care regarding $P_{\text {cuff, }}$ percentage of time spent with underinflation of tracheal cuff, and coefficient of variation of $P_{\text {cuff. }}$ However, the percentage of time spent with overinflation of tracheal cuff was significantly higher during continuous control compared with routine care.

One potential explanation for this result is the high frequency of $P_{\text {cuff }}$ control using the manometer, i.e., every $4 \mathrm{~h}$, during routine care. A recent prospective study performed in a cohort of 102 patients receiving invasive mechanical ventilation and manual control of $P_{\text {cuff }}$ using a manometer every $8 \mathrm{~h}$ found a lower percentage of time (18\%) spent within the target range [14]. However, this explanation is unlikely because our results are in agreement with those of another recent trial, in which $P_{\text {cuff }}$ was controlled using a manometer every $8 \mathrm{~h}$ [13]. Further, previous studies showed that each time a manometer is connected to the tracheal cuff, a sudden drop of $P_{\text {cuff }}$ is observed $[22,26]$. This is probably related to transient underinflation of tracheal cuff and might promote microaspiration of contaminated secretions [27]. Therefore, controlling $P_{\text {cuff }}$ more frequently in order to maintain it within the target range could probably not be recommended.

In spite of strictly applying instructions for user of the mechanical device, the percentage of time spent within the target range of $P_{\text {cuff }}$ was only $34 \%$. Previous studies using different devices to continuously control $P_{\text {cuff }}$ reported better performances and a percentage within the targeted range $>90 \%[19,20,22,28]$. Another potential explanation for the low efficiency of the device is the mechanism of $P_{\text {cuff }}$ control. This device uses the respiratory flow to inflate tracheal cuff during inspiration. Therefore, it is dependent on respiratory flow and airway pressure that may widely vary in critically ill patients. In addition, the key principle is probably an equilibrium be-

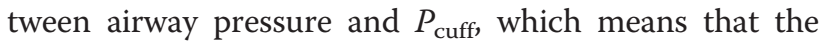
time constant of the system might play a role in the higher $P_{\text {cuff }}[29,30]$. Further, the exact $P_{\text {cuff }}$ target, using the mechanical device, could not be precisely determined or modified. In order to test the hypothesis that our results could be explained by the bad performance 
of the device in patients with high airway pressures, we repeated all statistical analyses after exclusion of patients with the highest mean airway pressure but found similar results. This might be explained by the fact that high airway pressure could have occurred during only a short period of the total recording time and the relatively small number of included patients.

To our knowledge, our study is the first to evaluate the PressureEasy mechanical device, and its results suggest that the device should not be used in critically ill patients. Our study also raises the important question of why medical devices such as tracheal tubes or $P_{\text {cuff }}$ controllers could obtain the Communauté Européenne (CE) mark and be used in critically ill patients without any published clinical data proving their efficiency. Nevertheless, clinical evaluation before CE mark could be very complex and might reduce the development of new technologies.

No significant difference was found in coefficient of variation of $P_{\text {cuff }}$ between the two study periods. However, $P_{\text {cuff }}$ variation in study patients was relatively small and had probably no clinical impact, except in those patients with $P_{\text {cuff }}$ around 20 or $30 \mathrm{cmH}_{2} \mathrm{O}$.

Some limitations of our study should be acknowledged. First, this was a single-center study. All study patients received assist-control ventilation, and a high proportion of them were sedated. Therefore, our results may not be generalized to patients in other ICUs, especially to nonsedated patients receiving pressure support ventilation. Second, the number of studied patients was relatively small. However, $P_{\text {cuff }}$ was continuously recorded for $48 \mathrm{~h}$. In addition, the number of included patients was calculated based on our hypothesis before starting the study. Third, because of the study design, namely the fact that every patient was its own control, we could not evaluate complications related to underinflation or overinflation of tracheal cuff. However, we think that this design is probably optimal as a first step in order to validate the device, before performing larger studies evaluating its impact on complications. Our study design allowed adjustment of patientrelated confounding factors, such as tracheal anatomy, tracheal tube size, and airway pressure. Fourth, we excluded patients who could not be included during the first $48 \mathrm{~h}$ of their invasive mechanical ventilation. This exclusion criterion was selected because duration of intubation was identified as a risk factor for underinflation of tracheal cuff [14]. Fifth, we did not collect $P_{\text {cuff }}$ values obtained manually during the routine care period and did not evaluate the relationship between manometer connection and any drop in $P_{\text {cuff. }}$ However, several previous well-designed and performed studies have clearly confirmed this relationship [22, 26]. Finally, Glascow Coma score was used to evaluate consciousness in study patients. However, a sedation score would have been more appropriate in sedated patients.

\section{Conclusions}

The PressureEasy ${ }^{\circ}$ device did not demonstrate a better control of $P_{\text {cuff }}$ within the target range $\left(20-30 \mathrm{cmH}_{2} \mathrm{O}\right)$, compared with routine care using a manometer every $4 \mathrm{~h}$. Moreover, the percentage of time spent with overinflation of tracheal cuff was more frequent using this device compared with routine care, which might increase the risk for tracheal ischemic lesions. Therefore, the use of this device could not be recommended in critically ill patients. Further large studies are required to confirm our results.

\section{Abbreviations}

CE: Communauté Européene; HPLV: high-volume low-pressure; $P_{\text {cuff: }}$ cuff pressure; PEP: positive expiratory pressure; SAPS: simplified acute physiology score; SOFA: sequential organ failure assessment; PVC: polyvinyl chloride.

\section{Competing interests}

$\mathrm{SN}$ is a member of the advisory board in Covidien. The other authors declare that they have no competing interests.

\section{Authors' contributions}

$S N, J V, A A$, and IML designed the study. AR and PS included the patients, performed the pressure recording, and collected the data. JDJ performed the data analyses. SN and IML coordinated the study. SN performed the statistical analysis and drafted the manuscript. All authors participated in the data interpretation and read and approved the final manuscript.

\section{Author details}

${ }^{1}$ Critical Care Center, Hospital de Sabadell, Universidad Autonoma de Barcelona, CIBER enfermedades respiratorias, Corporació Sanitaria Parc Tauli, Parc Tauli 1, 08208 Sabadell, Spain. ${ }^{2}$ Critical Care Center, R. Salengro Hospital, CHRU de Lille, rue E. Laine, 59037 Lille Cedex, France. ${ }^{3}$ Clinical Investigation Center-Innovative Technologies, INSERM CIC-IT 807, University Hospital of Lille, 152 rue du Dr. Yersin, 59120 Loos, France. ${ }^{4}$ Multidisciplinary Intensive Care, St James's University Hospital, Dublin, Ireland.

Received: 6 January 2015 Accepted: 20 May 2015

Published online: 02 June 2015

\section{References}

1. Esteban A, Frutos-Vivar F, Muriel A, Ferguson ND, Peñuelas O, Abraira V, et al. Evolution of mortality over time in patients receiving mechanical ventilation. Am J Respir Crit Care Med. 2013;188:220-30.

2. Touat L, Fournier C, Ramon P, Salleron J, Durocher A, Nseir S. Intubation-related tracheal ischemic lesions: incidence, risk factors, and outcome. Intensive Care Med. 2013;39:575-82.

3. Nseir S, Zerimech F, Jaillette E, Artru F, Balduyck M. Microaspiration in intubated critically ill patients: diagnosis and prevention. Infect Disord Drug Targets. 2011;11:413-23.

4. Blot SI, Poelaert J, Kollef M. How to avoid microaspiration? A key element for the prevention of ventilator-associated pneumonia in intubated ICU patients. BMC Infect Dis. 2014;14:119.

5. Beuret $P$, Philippon B, Fabre $X$, Kaaki M. Effect of tracheal suctioning on aspiration past the tracheal tube cuff in mechanically ventilated patients. Ann Intensive Care. 2012;2:45.

6. Craven DE, Chroneou A, Zias N, Hjalmarson KI. Ventilator-associated tracheobronchitis: the impact of targeted antibiotic therapy on patient outcomes. Chest. 2009;135:521-8.

7. Nair GB, Niederman MS. Ventilator-associated pneumonia: present understanding and ongoing debates. Intensive Care Med. 2014;31:34-48.

8. Hameed AA, Mohamed H, Al-Mansoori M. Acquired tracheoesophageal fistula due to high intracuff pressure. Ann Thorac Med. 2008;3:23-5. 
9. Seegobin RD, van Hasselt GL. Endotracheal cuff pressure and tracheal mucosal blood flow: endoscopic study of effects of four large volume cuffs. Br Med J. 1984;288:965-8.

10. Combes X, Schauvliege F, Peyrouset O, Motamed C, Kirov K, Dhonneur G, et al. Intracuff pressure and tracheal morbidity: influence of filling with saline during nitrous oxide anesthesia. Anesthesiology. 2001;95:1120-4.

11. Jaillette E, Martin-Loeches I, Artigas A, Nseir S. Optimal care and design of the tracheal cuff in the critically ill patient. Ann Intensive Care. 2014;4:7.

12. Guidelines for the management of adults with hospital-acquired, ventilator-associated, and healthcare-associated pneumonia. Am J Respir Crit Care Med 2005, 171:388-416

13. Nseir S, Zerimech F, De Jonckheere J, Alves I, Balduyck M, Durocher A. Impact of polyurethane on variations in tracheal cuff pressure in critically ill patients: a prospective observational study. Intensive Care Med. 2010;36:1156-63.

14. Nseir S, Brisson H, Marquette C-H, Chaud P, Di Pompeo C, Diarra M, et al. Variations in endotracheal cuff pressure in intubated critically ill patients: prevalence and risk factors. Eur J Anaesthesiol. 2009;26:229-34.

15. Lizy C, Swinnen W, Labeau S, Poelaert J, Vogelaers D, Vandewoude K, et al. Cuff pressure of endotracheal tubes after changes in body position in critically ill patients treated with mechanical ventilation. Am J Crit Care. 2014;23:e1-8.

16. Sole ML, Su X, Talbert S, Penoyer DA, Kalita S, Jimenez E, et al. Evaluation of an intervention to maintain endotracheal tube cuff pressure within therapeutic range. Am J Crit Care. 2011;20:109-17. quiz 118.

17. Rubes D, Klein AA, Lips M, Rulisek J, Kopecky P, Blaha J, et al. The effect of adjusting tracheal tube cuff pressure during deep hypothermic circulatory arrest: a randomised trial. Eur J Anaesthesiol. 2014;31:452-6.

18. Servin SO, Barreto G, Martins LC, Moreira MM, Meirelles L, Neto JAC, et al. Atraumatic endotracheal tube for mechanical ventilation. Rev Bras Anestesiol. 2011;61:311-9.

19. Duguet A, D'Amico L, Biondi G, Prodanovic H, Gonzalez-Bermejo J, Similowski T. Control of tracheal cuff pressure: a pilot study using a pneumatic device. Intensive Care Med. 2007;33:128-32.

20. Nseir S, Duguet A, Copin M-C, De Jonckheere J, Zhang M, Similowski T, et al. Continuous control of endotracheal cuff pressure and tracheal wall damage: a randomized controlled animal study. Crit Care. 2007;11:R109.

21. Brisson H, Bouhemad B, Lu Q, ROUBY JJ. Comparison of two automated endotracheal tube cuff pressure regulators in intubated critically ill patients. (abstract). Intensive Care Med. 2011;37:296

22. Farré $R$, Rotger M, Ferre M, Torres A, Navajas D. Automatic regulation of the cuff pressure in endotracheally-intubated patients. Eur Respir J. 2002;20:1010-3.

23. Weiss M, Doell C, Koepfer N, Madjdpour C, Woitzek K, Bernet V. Rapid pressure compensation by automated cuff pressure controllers worsens sealing in tracheal tubes. Br J Anaesth. 2009;102:273-8.

24. Chenelle CT, Oto J, Sulemanji D, Fisher DF, Kacmarek RM. Evaluation of an automated endotracheal tube cuff controller during simulated mechanical ventilation. Respir Care. 2015;60:183-90.

25. De Jonckheere J, Logier R, Dassonneville A, Delmar G, Vasseur C. PhysioTrace: an efficient toolkit for biomedical signal processing. Conf Proc Annu Int Conf IEEE Eng Med Biol Soc IEEE Eng Med Biol Soc Annu Conf. 2005;7:6739-41.

26. Memela ME, Gopalan PD. Variations in endotracheal tube cuff pressure: is 8-hourly monitoring enough? South African J Crit Care. 2014;30:35-40.

27. Nseir S, Zerimech F, Fournier C, Lubret R, Ramon P, Durocher A, et al. Continuous control of tracheal cuff pressure and microaspiration of gastric contents in critically ill patients. Am J Respir Crit Care Med. 2011;184:1041-7.

28. Jaillette E, Zerimech F, De Jonckheere J, Makris D, Balduyck M, Durocher A, et al. Efficiency of a pneumatic device in controlling cuff pressure of polyurethane-cuffed tracheal tubes: a randomized controlled study. BMC Anesthesiol. 2013;13:50

29. Bolzan DW, Gomes WJ, Peixoto TCA, Faresin SM, Carvalho AC, De Paola $A A V$, et al. Clinical use of the volume-time curve for endotracheal tube cuff management. Respir Care. 2014;59:1628-35.

30. Richard J-CM, Mercat A. Tracheal cuff management as part of a lung-protective strategy. Respir Care. 2014;59:1810-1.

\section{Submit your manuscript to a SpringerOpen ${ }^{\odot}$ journal and benefit from:}

- Convenient online submission

- Rigorous peer review

- Immediate publication on acceptance

- Open access: articles freely available online

- High visibility within the field

- Retaining the copyright to your article

Submit your next manuscript at $>$ springeropen.com 